\title{
ON SEIFFERT-LIKE MEANS
}

\section{ALFRED WITKOWSKI}

Abstract. We investigate the representation of homogeneous, symmetric means in the form

$$
M(x, y)=\frac{x-y}{2 f\left(\frac{x-y}{x+y}\right)} .
$$

This allows for a new approach to comparing means. As an example, we provide optimal estimate of the form

$$
(1-\mu) \min (x, y)+\mu \max (x, y) \leqslant M(x, y) \leqslant(1-v) \min (x, y)+v \max (x, y)
$$

and

$$
M\left(\frac{x+y}{2}-\mu \frac{x-y}{2}, \frac{x+y}{2}+\mu \frac{x-y}{2}\right) \leqslant N(x, y) \leqslant M\left(\frac{x+y}{2}-v \frac{x-y}{2}, \frac{x+y}{2}+v \frac{x-y}{2}\right)
$$

for some known means.

We also introduce an integral operator on the set of means and investigate its properties.

Mathematics subject classification (2010): 26D15.

Keywords and phrases: Seiffert mean, logarithmic mean, Seiffert function.

\section{REFERENCES}

[1] P.F. Byrd And M.D. Friedman. Handbook of Elliptic Integrals for Engineers and Scientists. Springer, New York, 1971.

[2] Y. CHU AND W. XIA. Solution of an open problem for Schur convexity or concavity of the Gini mean values. Sci. China Ser. A, 52, 10 (2009), 2099-2106.

[3] Y.-M. Chu And S.-W. Hou. Sharp bounds for Seiffert mean in terms of contraharmonic mean. Abstr. Appl. Anal., Art. ID 425175, (2012).

[4] Y.-M. ChU, M.-K. WANG AND W.-M. Gong. Two sharp double inequalities for Seiffert mean. J. Inequal. Appl., 2011:44 (2011).

[5] Y.-M. ChU, M.-K. WANG AND Z.-K. WANG. A best-possible double inequality between Seiffert and harmonic means. J. Inequal. Appl., 2011:94 (2011).

[6] Y.-M. Chu, C. Zong AND G.-D. WANG. Optimal convex combination bounds of Seiffert and geometric means for the arithmetic mean. J. Math. Inequal., 5, 3 (2011), 429-434.

[7] V. ČUlJaK, I. Franjić, G. RoQIA AND J. PEČARIĆ. Schur-convexity of averages of convex functions. J. Inequal. Appl., 2011:581918 (2011).

[8] B. FARHI. Algebraic and topological structures on the set of mean functions and generalization of the AGM mean. Colloq. Math., 132, 1 (2013), 139-149.

[9] S. GAO, H. GAO AND W. SHI. Optimal convex combination bounds of the centroidal and harmonic means for the Seiffert mean. Int. J. Pure Appl. Math, 70, 5 (2011), 701-709.

[10] C.F. Gauss. Werke. Bd. 3, Königlichen Gesell. Wiss., Göttingen, 1876, 361-403.

[11] A. W. Marshall, I. OlKin AND B. C. ARnOld. Inequalities: theory of majorization and its applications. Springer Series in Statistics. Springer, New York, second edition, 2011.

[12] E. Neuman. Inequalities involving inverse circular and inverse hyperbolic functions II. J. Math. Inequal., 4, 1 (2010), 11-14.

[13] E. Neuman. A one-parameter family of bivariate means. J. Math. Inequal., 7, 3 (2013), 399-412.

[14] E. Neuman And J. SÁndor. On the Schwab-Borchardt mean. Math. Pannon., 14, 2 (2003), 253-266. 
[15] I. Pinelis. L'Hospital type rules for monotonicity, with applications. J. Inequal. Pure Appl. Math., 3, 1 (2002).

[16] J. SÁndor. On certain inequalities for means, II. J. Math. Anal. Appl., 199, 2 (1996), 629-635.

[17] J. SÁndor. On certain inequalities for means, III. Arch. Math. (Basel), 76, 1 (2001), 34-40.

[18] J. SÁndor. Über zwei Mittel von Seiffert, Die Wurzel, 36, 5 (2002), 104-107.

[19] J. SÁNDOR AND E. NeUMAN. On certain means of two arguments and their extensions, Int. J. Math. Math. Sci., 2003(16) (2003), 981-993.

[20] H.-J. SEIFFERT. Werte zwischen dem geometrischen und dem arithmetischen Mittel zweier Zahlen. Elem. Math., 42, 4 (1987), 105-107.

[21] H.-J. SeIfFerT. Aufgabe $\beta 16$. Die Wurzel, 29 (9+10) (1995), 221-222.

[22] H.-N. ShI, M. Bencze, S.-H. Wu AND D.-M. LI. Schur convexity of generalized Heronian means involving two parameters. J. Inequal. Appl., 2008:879273 (2008).

[23] M.-K. WANG, Y.-M. ChU AND B.-Y. LiU. Sharp inequalities for the Neuman-Sandor mean in terms of arithmetic and contra-harmonic means. Rev. Anal. Numér. Théor. Approx., 42, 2 (2013), 115-120.

[24] A. Witkows Ki. Monotonicity and convexity of S-means. Math. Inequal. Appl., 13, 1 (2010), 33-42. 